Original Article

\title{
Medico-Legal Cases (MLC) Presented at a Tertiary Care Center and Acute Symptoms of Post-Traumatic Stress Disorder among the Survivors
}

\author{
Rabail Altaf1, Muhammad Rafique Shaikh', Asghar Ali Memon², Nargis Priya', Farah Malik², \\ Muhammad Ayoub Jogi ${ }^{1}$, Kiran Abbas ${ }^{4}$ \\ Departments of ${ }^{1}$ Forensic Medicine and ${ }^{2}$ Community Medicine, Gambat Medical College, Gambat, Sindh \\ ${ }^{3}$ Department of Biochemistry, Gambat Medical College, Sindh and Department of Medicine, Liaquat \\ College of Medicine and Dentistry, ${ }^{4}$ Department of Medicine, Jinnah Postgraduate Medical Center, \\ Karachi - Pakistan
}

\section{ABSTRACT}

Objectives: An observational, prospective study was conducted to determine the incidence and risk factors associated with victims of physical assault and symptoms of post-traumatic stress disorder (PTSD).

Material \& Methods: All the registered medico-legal cases reported to the emergency department of Gambat hospital were included in the study. The data was collected on a predefined questionnaire including age, gender, mode of injury, weapon of the injury, type of assault (blunt or penetrating), firearm injuries, and road traffic accidents from medico-legal registers. Impact of Event Scale (IES) was used to assess Posttraumatic stress disorder.

Results: The mean age (SD) of victims was 29.3 (10.25) years. Blunt injuries were experienced by 47 (31.33\%) victims. The majority of the victims suffered road traffic collision injuries, 59 (39.33\%). Forty-eight (32\%) victims had substantially higher IES scores (above 37) that confirmed severe PTSD that may contribute to the suppression of the immune system's functioning among survivors. The majority of the victims were between 18 and 40 years.

Conclusion: The most common cases were related to road traffic collisions followed by blunt injuries. The incidence rate of PTSD was also prevalent in these individuals. Thus, strategies should be developed to prevent such incidents and those who suffer from such traumatic events must be offered psychiatric consultation.

Keywords: Critical Medicine, Injury, Medico-Legal Cases (MLC), Post-Traumatic Stress Disorder.

\section{Corresponding Author: Rabail Altaf}

Forensic Medicine department, Gambat Medical College, Gambat, Sindh - Pakistan

Email:rabailmuslim@gmail.com
Date of Submission: 02-05-2021

Date of Revision: 12-06-2021

Date of Online Publishing: 30-06-2021

Date of Print: 30-06-2021 


\section{INTRODUCTION}

Medico-legal cases are those cases that occur because of an injury, which warrants an investigation by the relevant law and order authorities, the contribution of which helps in determining the cause of the injury. ${ }^{1}$ Injury that fall under the umbrella of medico-legal cases include all those incidences that point towards a possible criminal activity, such as firearm injuries, injury inflicted by a blunt or sharp-edged weapon, homicide, poisoning, and sexual assault. ${ }^{2}$ Treating medico-legal cases are essential for clinical practice and form a large chunk of medical emergencies. $^{3}$

In a medico-legal case, the doctor on duty is required to collect all the relevant history and conduct a thorough exam, after which the relevant law enforcement authorities are involved to evaluate the cause and establish responsibility for the case at hand. ${ }^{4}$ Medico legal cases commonly present to the casualty department and form an important portion of all emergency cases brought to teaching hospitals. ${ }^{5}$

A large component of workload in medical hospitals and institutes comprises the legal and clinical services that are provided to cater to medico-legal cases. ${ }^{5}$ Analyzing medico-legal cases and studying its occurrence plays an essential role in understanding its causes and preventing its occurrence, along with evaluating the crime rates of different areas. ${ }^{6}$ Studying the rate of crime and the type of criminal cases that occur provides an adequate understanding of the social problems that prevail in society. The cases that present at the healthcare centers depict the extent of social issues and the height of intolerance that exists in a community. ${ }^{7}$

Recent studies have shown that in Pakistan, people in their third decade of life, are the most affected by criminal offenses (37.6\%). Of the injuries inflicted as a result of criminal offenses, the most common were those by blunt weapons (64.77\%) which were followed by firearm injuries (9.3\%) and sharp weapon injuries (8.8\%). On the other hand, burns (0.2\%) and poisoning (0.55\%) formed a much smaller chunk of medico-legal cases. $^{8}$

The survivors of a physical assault or a road traffic accident are at risk of developing psychological problems later in life as well as acutely. A study conducted by Elklit and Brink explored the impact of stress due to physical assault as a risk factor for post-traumatic stress disorder among survivors. ${ }^{9}$ The majority of the victims of abuse and physical assault are expected to be not only physically but also psychologically traumatized. They are at risk of developing mental health problems.

Despite the high prevalence of medico-legal cases in the country, it is still not considered a significant public health concern. ${ }^{10}$ It is essential that the data collected to be used to determine the socio-economic implications of medico-legal cases and develop strategies to prevent its occurrence in the future.

The present study was conducted to assess the cases at the department of forensics at Gambat Medical College, Sindh, Pakistan. We evaluated the different categories of medico-legal cases and the characteristics of the victims documented. The objective was to determine the incidence and the risk factors associated with medico-legal cases presented at our local center.

\section{MATERIAL AND METHODS}

\section{Study Design \& Setting}

This was an observational and prospective study conducted at the Forensic Department and Radiology Department, Gambat, Sindh, Pakistan between January 2019 to January 2020. Ethical approval from the concerned department was obtained prior to the study.

\section{Inclusion Criteria}

All the registered medico-legal cases reported to the emergency department of Gambat hospital 
were included in the study. Only the cases reported at MLO were included irrespective of the cause of trauma.

\section{Exclusion Criteria}

Records with incomplete data were excluded from the study.

\section{Sample Size Calculations}

The sample size was calculated using Select Statistics Calculator by keeping the rate of PTSD among victims of Physical Assault as 22\%, a confidence interval of $92 \%$, and a margin of error of $6 \%$. The calculated sample size was $146 .{ }^{9}$

\section{Data Collection}

The data was collected with informed consent from the patients. The data was collected on a predefined questionnaire including age, gender, social status, education, occupation, residence (urban or rural), time of injury, time of presentation/admission, mode of injury, weapon of the injury, type of assault (blunt or penetrating), firearm injuries and road traffic accidents from medico-legal registers. Posttraumatic stress disorder (PTSD) was measured one month after the medico-legal incident. The impact of event scale (IES) was used to assess the severity of acute symptoms of PTSD. ${ }^{11}$ The impact of event scale (IES), a fifteen-item scale is used for determining the absence or presence of intrusive thoughts and the participants' response to traumatic events of varying severity by different groups. The items were scored from 0 to 5 and depending upon the score, the severity of PTSD was determined. The participants were divided into the following, i) Subclinical range, ii) Mild range, iii) Moderate range, iv) Severe range. The scale contains an intrusion (Cronbach's alpha for the present study $=.85$ ) and avoidance (alpha $=.85$ ) subscale, and all items can be summed to provide a total scale score (alpha=.92).

\section{Data Analysis}

The data analysis was performed using Statistical Package for Social Sciences (SPSS version 26). Findings were presented in tabular and graphical forms. The association between different types of injuries and IES scores was determined by applying the Chi-Square test. Similarly, the association between different age groups and types of injuries was determined. All categorical data was described as frequency and percentages while all non-categorical data was presented as mean and standard deviation. A p-value of $\leq 0.05$ was considered statistically significant.

\section{RESULTS}

\section{Demographics \& Clinical Characteristics}

A total of 150 medico-legal cases were reported during the study period. The current study reported a mean age (SD) of victims as 29.3 (10.25) years. The rate of poisoning ingestion, both incidental and intentional was $4.67 \%$. Trauma or assaults due to sharp weapons/objects were found in 28 cases (18.67\%). Blunt injuries were experienced by $47(31.33 \%)$ victims. The majority of the victims suffered road traffic accident injuries, 59 (39.33\%). The mean score of Impact of Event Scale (IES) was 27.5 (18.56). See Table 1 for detailed MLC (medico-legal cases) categories.

Table 1: The sociodemographic and clinical parameters of victims presented in the Medico-legal department $(n=150)$.

\section{Variables} n (\%)

Mean Age (SD) in years

$29.3(10.25)$

Mean Impact of Event Scale Score

Gender

Male

Female

$27.5(18.56)$

89 (59.3\%)

$61(40.7 \%)$

Trauma Categories

Poisoning

Sharp weapons

7 (4.67\%)

Blunt injuries 
Firearm injuries $9(6.00 \%)$

Road Traffic Accidents

\section{Association between Demographic}

\section{Characteristics and Type of Injury}

It was found that the majority of the victims who had poison ingestion were older than 18 years.

Only about $14.29 \%$ were younger than 18 years of age. The majority of the victims who experienced assault with a sharp weapon or firearm injuries or a road traffic accident were between 18 to 40 years. About $3 / 4$ th of those who suffered blunt injuries were also between 18 to 40 years. See Table 2 for details.

Table 2: Correlation of age group and type of injury experienced by the victims.

\begin{tabular}{lcccccc} 
Age groups & Poisoning & Sharp Weapons & Blunt Injuries & Firearm Injuries & $\begin{array}{c}\text { Road Traffic } \\
\text { Accidents }\end{array}$ & p-value \\
\hline$<18$ years & $1(14.29 \%)$ & $11(39.29 \%)$ & $10(21.28 \%)$ & $3(33.33 \%)$ & $12(20.34 \%)$ & $<0.05^{\star}$ \\
$18-40$ years & $3(42.86 \%)$ & $16(57.14 \%)$ & $34(72.34 \%)$ & $5(55.56 \%)$ & $41(69.49 \%)$ & (*Significant \\
$>40$ years & $3(42.86 \%)$ & $1(3.57 \%)$ & $3(6.38 \%)$ & $1(11.11 \%)$ & $6(10.17 \%)$ & result)
\end{tabular}

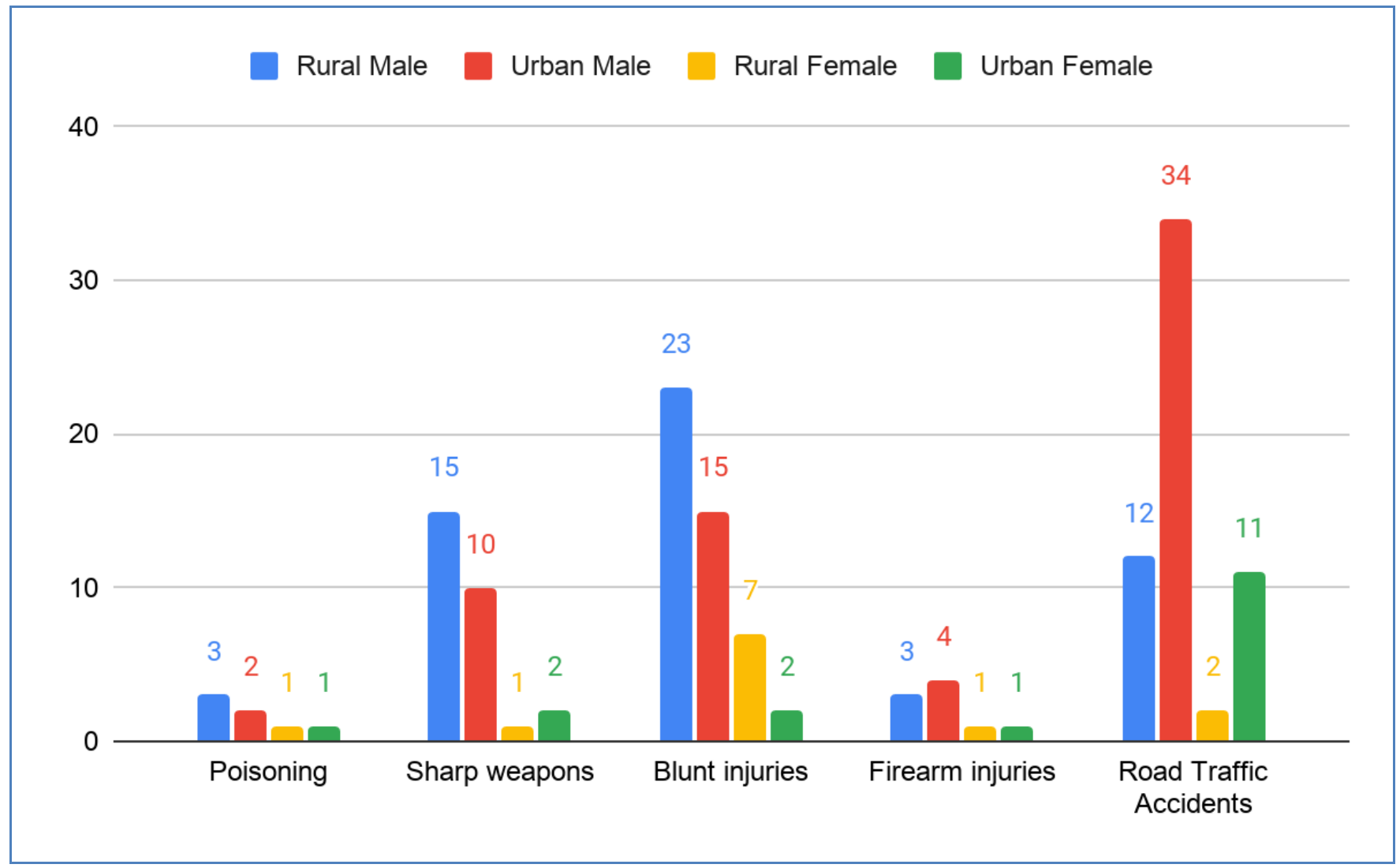

Figure 1: Distribution of MLC categories according to the residence of victims ( $p$-value $<0.05$ ). 
Table 3: Impact of event scale and its distribution according to the types of injuries.

\begin{tabular}{|lcccccc|} 
IES Score \& Severity of & Poisoning & $\begin{array}{c}\text { Sharp } \\
\text { weapons }\end{array}$ & Blunt injuries & $\begin{array}{c}\text { Firearm } \\
\text { injuries }\end{array}$ & $\begin{array}{c}\text { Road Traffic } \\
\text { Accidents }\end{array}$ & p-value \\
\hline$<24$ ( & 1 & 4 & 7 & 2 & 9 & \\
24 or more & 4 & 10 & 12 & 3 & 12 & 0.648 \\
33 and above & 1 & 8 & 14 & 2 & 13 & \\
37 or more & 1 & 6 & 14 & 2 & 25 & \\
\hline
\end{tabular}

We reported the majority of road collision cases among male victims in urban settings whereas blunt injuries were more common among males in rural settings. Overall, the frequency of road traffic collision was more common in urban settings $(p<0.05)$.

\section{Post-traumatic Stress Disorder among Victims}

A total of 23 survivors had an IES score of less than 24 while 41 (27.3\%) of the survivors had scores higher than 24 which indicated clinical concern for PTSD. About 38 (25.3\%) patients had scores higher than 33 which represented a probable diagnosis of PTSD. Surprisingly, a total of 48 (32\%) victims had substantially higher IES scores (above 37) that confirmed severe PTSD that may contribute to the suppression of the immune system's functioning among survivors. According to the IES score, the current study reported a PTSD incidence of $32 \%$ among the survivors.

\section{DISCUSSION}

A total of 150 medico-legal cases that were presented to the casualty department of a tertiary care hospital (Gambat), were analyzed. The study reported the mean age of the victims to be 30 years. According to the study, the maximum number of cases reported were those resulting from road traffic collisions (39.33\%). This was followed by blunt injuries (31.33\%) and sharp weapon injuries (18.67\%). The findings were consistent with those of the study conducted by
Malik et al. which reported road traffic accidents (38\%) to be the most common cause of medicolegal cases presenting in a tertiary care hospital in Rawalpindi. This was followed by injuries due to physical assaults (32\%) and the use of sharp weapons (19\%). ${ }^{12}$

The findings in Pakistan are inconsistent with that of the UK, where the prevalence of penetrating trauma $(86.8 \%)$ is the major cause of medico-legal cases, followed by firearm injuries $(13.3 \%) .^{13}$ The occurrence of firearm injuries in the present study is very low (9\%), which is consistent with other similar studies conducted in Pakistan. ${ }^{14}$ However, these findings oppose the studies performed in the western world, where firearm injuries are more common. ${ }^{15}$

A study conducted in the city of Abbottabad revealed that the majority of reported medicolegal cases were those that followed an injury due to a blunt weapon (65.85\%), with road traffic accidents consisting of $9.34 \%$ of the total cases. ${ }^{16}$ These findings were inconsistent with that of the present study, which reported cases due to blunt injury to be $31.33 \%$. When compared with the current study, it can be observed that the most common cause of medico-legal cases in rural areas is a result of blunt trauma, while in urban areas, the most common cause is road traffic accidents.

A study of the rural areas of Bahawalpur indicated that the most common cause of medico-legal cases in the area was due to blunt trauma (55\%), while road traffic accidents comprised only $5 \%$ of all cases. ${ }^{17}$ These findings are consistent with the results of the current 
study, which indicates the most common cause of medico-legal cases to be blunt trauma in rural areas. Such cases are more common in rural areas mainly due to a lower literacy rate, frequent instances of quarreling, social, tribal, and cultural customs. $^{18}$

The study suggested that cases of poisoning were most common in people over the age of 18 years. This finding was in accordance with that of the study conducted by Khan et al., which reported $19 \%$ cases of poisoning in patients under $18 .{ }^{19}$ This finding can be compared with the present study, which reported $14.29 \%$ poisoning cases in patients younger than 18 years.

Of the cases of assault, $18.67 \%$ made use of sharp weapons, while a majority $(31.33 \%)$ of cases of assault occurred by means of a blunt weapon. These findings were in accordance with the study by Haridas et al. which suggests that the most frequently used weapon for assault was a blunt object, which was followed by a sharp-edged weapon. ${ }^{20}$

Our study hints at a relationship between increased risk of PTSD among survivors and the mode of injury i.e. penetrating or blunt. However, we failed to find any significant findings which could be due to small sample size. Further largescale studies should be conducted to explore the psychological consequences of a physical assault or a motor vehicle accident. The current study reported a PTSD incidence of $32 \%$ among the survivors. In accordance with our study Johansen et al, found that $31 \%$ of victims of physical assault had probable PTSD as indicated by IES-15. The severity of the assault and a positive history of previous assaults were associated with the occurrence of PTSD. Similarly, the authors revealed a lack of social support as a predictor of PTSD among survivors. ${ }^{21}$

The present study concluded road traffic accidents to be one of the significant causes of medico-legal cases. It not only contributes to physical harm but also results in psychological deficits.

\section{CONCLUSION}

This is the first study done at Gambat (Sindh) evaluating the burden of medico-legal cases and their aftermath mental health effects. The most common cases were related to road traffic collisions followed by blunt injuries. The incidence rate of PTSD was also prevalent in these individuals. Thus, strategies should be developed to prevent such incidents and those who suffer from such traumatic events must be offered psychiatric consultation.

\section{REFERENCES}

1. Brahmankar TR, Sharma SK. A record based study of frequency and pattern of medico-legal cases reported at a tertiary care hospital in Miraj. International Journal of Community Medicine and Public Health, 2017; 4 (4): 1348-52.

2. Sandeep KS, Ranjit TM, Deshpande VL, Dilip WR. Profile of Medico-Legal Cases at a Tertiary Care Hospital in Ahmed Nagar, Maharashtra. Indian Journal of Forensic Medicine and Pathology, 2015; 1; 8 (4): 113.

3. Singh P, Verma SK. Profile of Medico legal Cases Admitted at a Newly Established Rural Medical College Hospital of Central India. Medico-Legal Update, 2015; 15 (1): 111-115.

4. Siddappa SC, Datta A. A Study Pattern of Medicolegal Cases Treated at a Tertiary Care Hospital in Central Karnataka. Indian J Forensic Comm Med. 2015; 2 (4): 193-197.

5. Timsinha S, Kar SM, Baral MP, Ranjitkar M. Profile of Pattern of Medico-Legal Cases in the Casualty of A Teaching Hospital of Western Region of Nepal. J Indian Acad Forensic Med. 2015; 37 (1): 46-49.

6. Saxena A, Kumar V, Chaudhary SR, Singh J, Awasthi $\mathrm{S}$. Pattern of medico-legal cases in the casualty department of a teaching hospital, Bareilly, UttarPradesh. Journal of Indian Academy of Forensic Medicine, 2015; 37 (4): 338-40. 
7. Mir MS, Jan FA, Yatoo GH, Khalil I, Ganai S, Irshad $\mathrm{H}$. Profile and Pattern of Medico-Legal Cases in a Tertiary Care Hospital of North India. J Med Sci Clin Res. 2016; 4 (9): 2628-34.

8. Arif $M$, Rasool SH, Ali SM. PROFILE OF MEDICOLEGAL CASES. The Professional Medical Journal, 2017; 7; 24 (03): 366-9.

9. Elklit A, Brink O. Acute stress disorder as a predictor of post-traumatic stress disorder in physical assault victims. Journal of Interpersonal Violence, 2004 Jun; 19 (6): 709-26.

10. Kayani A, Fleiter JJ, King MJ. Underreporting of road crashes in Pakistan and the role of fate. Traffic Injury Prevention, 2014; 15 (1): 34-39.

11. Hosey MM, Leoutsakos JM, Li $X$, Dinglas VD, Bienvenu OJ, Parker AM, Hopkins RO, Needham DM, Neufeld KJ. Screening for posttraumatic stress disorder in ARDS survivors: validation of the Impact of Event Scale-6 (IES-6). Critical Care, 2019; 23 (1): 1-7.

12. Malik R, Atif I, Rashid F, Abbas M. An analysis of 3105 medico legal cases at tertiary care hospital, Rawalpindi. Pakistan Journal of Medical Sciences, 2017 Jul; 33 (4): 926.

13. Maguire $M$, McVie S. Crime data and criminal statistics: A critical reflection. The Oxford handbook of Criminology, 2017: 163-89.

14. Bhatti MA, Mahmood S, Hanif S. Profile of Medicolegal Cases Attending Trauma Center of District Headquarter Teaching Hospital,
Gujranwala. Esculapio, 2013; 9 (3): 146-9.

15. Saleem S, Haider A, Khan J, Saleem T. Study of fatal road traffic accidents: based on medico-legal autopsies. Gomal Journal of Medical Sciences, 2015 Mar. 31; 13 (1).

16. Jadoon OK, Shireen F, Seema N, Afzal E, Ahmad I, Irshad $\mathrm{R}$, et al. Types of medico-legal cases reported at the casualty department of Ayub Teaching Hospital Abbottabad. Journal of Ayub Medical College Abbottabad, 2020 Jan. 23; 32 (1): 51-3.

17. Cheema TN, Qasim AP, Abaid T, Anjum H, Munir U, Abbas Q. Profile of Medicolegal Cases in the Rural Areas of District Bahawalpur. Annals of Punjab Medical College (APMC). 2019; 13 (2): 104-7.

18. Kumar D, Siddaramanna TC, Parate SV, Hemanthraj MN. Retrospective Study of Profile of medico-legal cases in Tumkur region, Karnataka. Int J Biomed Adv Res. 2015; 6 (4): 339-40.

19. Khan NU, Pérez-Núñez $R$, Shamim N, Khan UR, Naseer $\mathrm{N}$, Feroze $\mathrm{A}$, et al. Intentional and unintentional poisoning in Pakistan: a pilot study using the Emergency Departments surveillance project. BMC Emergency Medicine, 2015 1; 15 (S2): S2.

20. Haridas SV, Pawale DA. A retrospective study of pattern of clinical Medico-legal cases registered at tertiary health care centre in Kolhapur district. J Forensic Med Sci Law, 2014; 23 (2): 1-5.

21. Johansen VA, Wahl AK, Eilertsen DE, Weisaeth $L$. Prevalence and predictors of post-traumatic stress disorder (PTSD) in physically injured victims of non-domestic violence. Social Psychiatry and Psychiatric Epidemiology, 2007; 1; 42 (7): 583-93.

\section{Additional Information}

Disclosures: Authors report no conflict of interest.

Ethical Review Board Approval: The study was conformed to the ethical review board requirements.

Human Subjects: Consent was obtained by all patients/participants in this study.

\section{Conflicts of Interest:}

In compliance with the ICMJE uniform disclosure form, all authors declare the following:

Financial Relationships: All authors have declared that they have no financial relationships at present or within the previous three years with any organizations that might have an interest in the submitted work.

Other Relationships: All authors have declared that there are no other relationships or activities that could appear to have influenced the submitted work. 


\section{AUTHORS CONTRIBUTIONS}

\begin{tabular}{|l|l|l|}
\hline Sr.\# & Author's Full Name & Intellectual Contribution to Paper in Terms of: \\
\hline 1. & Rabail Altaf & Study design and methodology. \\
\hline 2. & Muhammad Rafique Shaikh & Paper writing and data calculations. \\
\hline 3. & Asghar Ali Memon & Data collection and calculations. \\
\hline 4. & Muhammad Ayoub Jogi & Analysis of data and interpretation of results etc. \\
\hline 5. & Nargis Priya & Literature review and referencing. \\
\hline 6. & Farah Malik, Kiran Abbas & Analysis of data and quality insurer. \\
\hline & & \\
\hline
\end{tabular}

